\title{
Correction to: Health Effects of Climate Change through Temperature and Air Pollution
}

\author{
Jianing Lou ${ }^{1} \cdot$ Yangyang $\mathrm{Wu}^{1} \cdot$ Penghui Liu ${ }^{1} \cdot$ Sri Harsha Kota ${ }^{2} \cdot$ Lei Huang ${ }^{1}$
}

Published online: 7 November 2019

(C) Springer Nature Switzerland AG 2019

Correction to: Current Pollution Reports (2019) 5(3):144-158. https://doi.org/10.1007/s40726-019-00112-9

The original version of this article, unfortunately, contained an error. In the recently published paper, "Health Effects of Climate Change Through Temperature and Air Pollution," there was an error in the first paragraph of the Introduction.
The parenthetical text in the last sentence should be excluded from the sentence. The corrected sentence should read:

The former has direct data showing that it is brought about by climate change, and the latter is seriously disturbed by the temperature changes caused by climate change.

The authors apologize for this error.

The online version of the original article can be found at https://doi.org/ 10.1007/s40726-019-00112-9

Lei Huang

huanglei@nju.edu.cn

1 State Key Laboratory of Pollution Control and Resource Reuse, School of the Environment, Nanjing University, Xianlin Campus, 163 Xianlin Avenue, Nanjing 210023, China

2 Department of Civil Engineering, Indian Institute of Technology Delhi, New Delhi 110016, India 